\title{
A PRACTICAL MEASURE OF STOCK DENSITY IN WHITE AND RED PINE STANDS
}

\author{
By G. A. Mulloy \\ Dominion Forest Service, Ottawa, Canada
}

\begin{abstract}
The findings of $L$. $H$. Reineke that a number of trees per acre on average diameter plotted on double logarithmic paper provides a straight line graph whose slope remains constant for all sites, age-classes and most species are checked against twenty years' record of sample plot data most species are checked against twenty years record of sample plot data on this principle in thinning technique and in forest management is developed.

The practical application of these findings is shown. All that is necessary is to estimate the average diameter of the stand. The spacing for optimum development is then fixed.
\end{abstract}

TN STUDIES of yield, growth and thinning practice stock density is the most important factor. How many trees or what basal area per acre is the most desirable condition for maximum volume and value production? That is the problem which confronts the silviculturist and which is the basis for experimentation and thinning even-aged stands.

The so-called normal yield tables are clearly not the solution for this problem of stock density at various ages, and on various sites, because of the principles on which they are constructed. They do not take thinning into consideration-except, of course, natural stem number decrease. Moreover, they assume that the 20-year old natural stand, selected as normally stocked, will produce the 80 - or 100-year old stand also selected as normally stocked. This may or may not be true but it hardly seems likely. It is more than probable that the 80-year old stand selected as normally stocked developed from a 20-year old stand which in our judgment was understocked.

Such expressions as normal, under-or over-stocking are currently used by foresters, often with rather an indefinite significance. These terms are defined in Forest Terminology (1) as follows:

"Normal stock-The amount of material represented by the stands in a normal forest; practically, the contents of the normal age-classes as represented in normal yield tables.

Over stock-A growing stock greater than the normal stock. In natural regeneration, a condition of excessive number of individuals hindering each other in development retarding desirable differentiation into crown classes.

Under stock-A growing stock less than the normal growing stock."

These definitions are very vague since they depend upon the existence of normal yield tables. The usual method of evaluating density has been to compare the total basal area of a stand with that of yield tables for stands of the same age and site While some yield tables have been compiled for certain species they are not generally available and, moreover, are not based on managed forests. Their applicability is often in doubt, because the samples upon which they are based are biased both by the judgment of the person selecting them as to what constitute normal stands and by the availability of samples, especially in the older age-classes. 


\section{MEASURE OF STOCK DENSITY-MULLOY}

An index of density which is independent of both age and site is needed, so that experiments in silviculture, such as the development of thinning technique, may not be hindered by lack of site classification and suitable yield tables. Reineke (2) has developed such an index based on numbers of trees and average diameter and has shown that it is independent of age and site. He has shown too that for 12 species out of 14 examined, the slopes of the "NUMBER OF TREES/AVERAGE DIAMETER" curves plotted on double-logarithmic paper are identical. The height of these curves at a given diameter, however, varied with species. In all this work, except in one case, single examination plots were used. In the one curve the remeasure. ment data for two plots are shown and the line of development corresponds well with the reference curve. This index of density, however, has not been generally accepted, probably because it is so simple.

There are various other factors which might be used to develop such an index. Generally, basal area, above its maximum, is sensitive. That is, with increased age and volume and no outside disturbance, there is a decrease in total basal area because of increase in mortality. The basal area of plots which are generally considered as overstocked will fluctuate up and down around a high but indefinite point. It can be shown that basal area plotted on average diameter follows a definite curve which may be used as a reference curve and index of stocking.

With average diameter as the independent variable, either basal area or number of trees may be chosen as the dependent variable. When plotted over average diameter on double logarithmic paper, both will follow straight lines. Reineke has chosen number of trees because of the ease of converting to spacing and because of the difficulty of visualizing basal area.

Reineke's work, as pointed out above, was based almost entirely on single examination of stands. While the evidence of a straight line relation is more than adequate there is yet the criticism that it is not the development of the same plots which is being examined but comparison of data from many single-examination plots.

At the Petawawa Forest Experiment Station a large number of permanent sample plots have been established in even-aged white and red pine cover-type -chiefly in the Maianthemum-Corylus site-type. Many of these have been remeasured at regular intervals for over twenty years. Many, also, have been thinned. The object of this paper is to show how closely the trend of the curve,- "Number of Trees/Average Diameter"-for all these plots agrees with the findings of Reineke.

In Figure 1 the number of trees for a number of unthinned control plots of white and red pine at various ages has been plotted over average diameter. The points for each plot at the several ages have been connected by straight lines so that the direction of the development can be traced. Reineke's Reference Curve running through 1000 trees per acre at 10 inches average diameter has also been drawn. It will be remarked at once that the slope of all the plots follows in the general direction of Reineke's base curve. This is good evidence that the slope of Reineke's curve is correct for the white and red pine cover-types at Petawawa. 
Having determined this, the next step is to determine the maximum Stand Density Index (S.D.I.) for plots in the white pine-red pine cover-type. It will be noted that in Reineke's presentation the S.D.I. curve fitted was the maximum in all but one case. These maximum S.D.I.'s represent what is generally termed "overstocking" for the species, and do not represent the S.D.I. for optimum development in growth value.

In Figure 1 we are not considering rate of growth at all. It is the trend in development of any plot under natural conditions, whether considered as over- or under-stocked. Precise determination of the maximum S.D.I. is unimportant. These sample plots seem to indicate a 500 S.D.I. as the Petawawa maximum.

As shown by Reineke, the S.D.I. curves are represented by the equation: $\log N=-1.605 \log D+K$

where $\mathrm{N}$ is the number of trees per acre, $\mathrm{D}$ is the average diameter, and $\mathrm{K}$ is a constant varying with S.D.I. For an S.D.I. of 500, $\mathrm{K}$ becomes 4.304 . Additional curves are shown for S.D.I.'s of 500, 400, 300 and 200.

As a comparison with the Petawawa plots, Fig. 7 of Gevorkiantz's yield tables for white pine in Wisconsin (3) has been replotted in Figure 1. This shows almost perfect agreement with the line for S.D.I. 450, but represents the average density of the yield table plots rather than the maximum.

What is the significance of the 500 S.D.I. (Petawawa maximum)? It probably represents the greatest density which will be encountered in the white and red pine cover-type in this region, and as such serves as a rough basis for estimating severity of thinning necessary. The S.D.I. for optimum stand development certainly will be considerably below this maximum. The Petawawa control plots were selected as representing too dense stocking for optimum growth and were evidently falling off in diameter growth. It is evident that a 400 S.D.I. is not low enough for optimum growth, and it is probable that the best growth in managed red and white pine stands will result with a 300-350 S.D.I. The precise determination of this S.D.I. then should be one of the objects of our thinning research.

It is of interest to plot the results of twenty years of thinning practice at the Petawawa Forest Experiment Station in the white and red pine cover-type. Figure 2 shows the number of trees per acre over average diameter for a number of thinning series. The controls are also plotted for comparison in each case. In Section $A$ the data for four plots $(77,78,79$, and 80 ) are shown. Plot numbers are shown in brackets and ages of the stands at each plotted point. The development of each plot is shown by the lines joining these points. Plot 77 is the unthinned control. It will be noted that this plot moved along just below the reference curve, for only a short distance (average diameter growth) while the other three plots with heavy first thinnings and second light ones in the case of two plots and a heavy one on one plot, moved over twice the distance. Of course, most of this movement is due to the axe alone and does not represent actual volume or diameter growth. But if the plots are thinned so that the relation- "Number of Trees/Average Diameter"--fluctuates around the 300 line, another 15 years will see them well on the way to being 20 inches in diameter, while the 


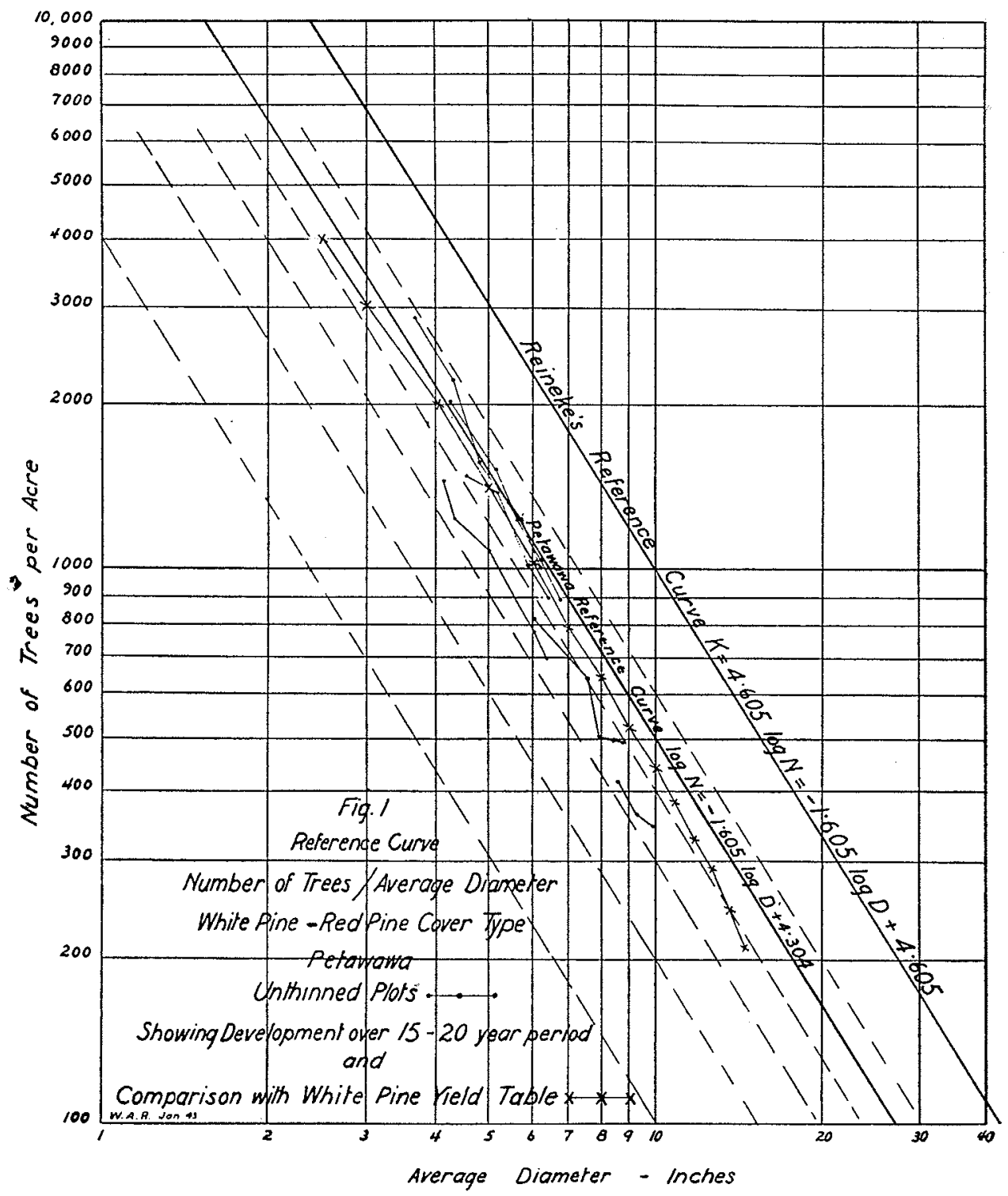

control plot will not yet have reached the 10 -inch point. It will be noted that on account of the logarithmic scale, the actual differences in number of trees per acre decrease greatly, as the average diameter becomes greater, so that stands kept at the 300 line will, at 20 inches, have about 100 trees per acre against 165 at the reference or 500 line. 
Although it is rather impractical to measure the benefit from thinning from these measures alone there would seem to be evidence that somewhere between the lines 300 and 400 would be the best density at which these plots should be maintained-probably around 320 S.D.I. All the plots were originally too heavily thinned and plot 78 with two heavy thinnings is altogether too heavily thinned as witness the increase in number of trees from age 45 to 50 , due to reproduction coming in. The behaviour of the thinned plots for the two 5-year periods between thinnings, where the line is almost horizontal, shows that the stands are attempting to hold density at or above maximum for good growth. Whether they would ever reach 500 S.D.I. after such heavy thinnings is doubtful.

As, unfortunately, no similar data covering managed (thinned) stands are available from yield tables it is interesting to plot on this graph (Figure 2, Section A) similar data for Scotch Pine Site I taken from Schlich (4). While a slight curve is shown, (no doubt due to the use of curved rather than basic data) it is probably significant that the trend is almost the same as the reference curve and that it closely follows the 300 S.D.I. line. Schlich's data are based on managed stands which have been regularly thinned every ten years throughout the life of the stand, and the total volume of thinnings is two-thirds as large as the final crop.

While data for unmanaged stands of Scotch pine in Europe are not available to compare with the level of the reference curve (500 S.D.I.) the yield table shows that very light thinnings were made at each 10-year interval, about 15 per cent being removed in the younger stands and five per cent in the older stands. It is probable then that the level of unthinned stands would be along the 400 S.D.I. It would appear, therefore, that according to European practice with Scotch pine our thinnings at 10-year intervals are too heavy, as in plots 78,79 , and 80 . Where only one or two thinnings are to be made, or where no thinnings have been made up to 35 to 40 years of age, it is a different matter.

Section B of Figure 2 shows another group of pine plots, only one of which has been thinned. General behavior shows that, for the 21 years that they have been under observation, the tendency is to remain around the 500 S.D.I. Probably they are overstocked, and $a_{*}$ heavier thinning would result in improvement in growth.

Section $\mathrm{C}$ shows an irregular group of five pine plots, all of which have been thinned. The phenomenal advance of plot 49 (37 to 57 years of age) along the general slope is to be noted, increasing from 5.1 inches to 10.4 inches in average diameter. The plot has been thinned three times. It will be noted also that this plot swings around the 350 S.D.I. Probably the last thinning has been a little too heavy and it should be allowed to come back to somewhere near the 400 S.D.I. before thinning again. In contrast, Plot 15 (40 to 60 years), although thinned twice and also kept near the 350 S.D.I., has not advanced very far along the slope, growing only from 6 inches to 9 inches in twenty years.

Section D shows a trio of older pine plots. These were not regular thinnings but an experiment in the influence of various degrees of shade upon 


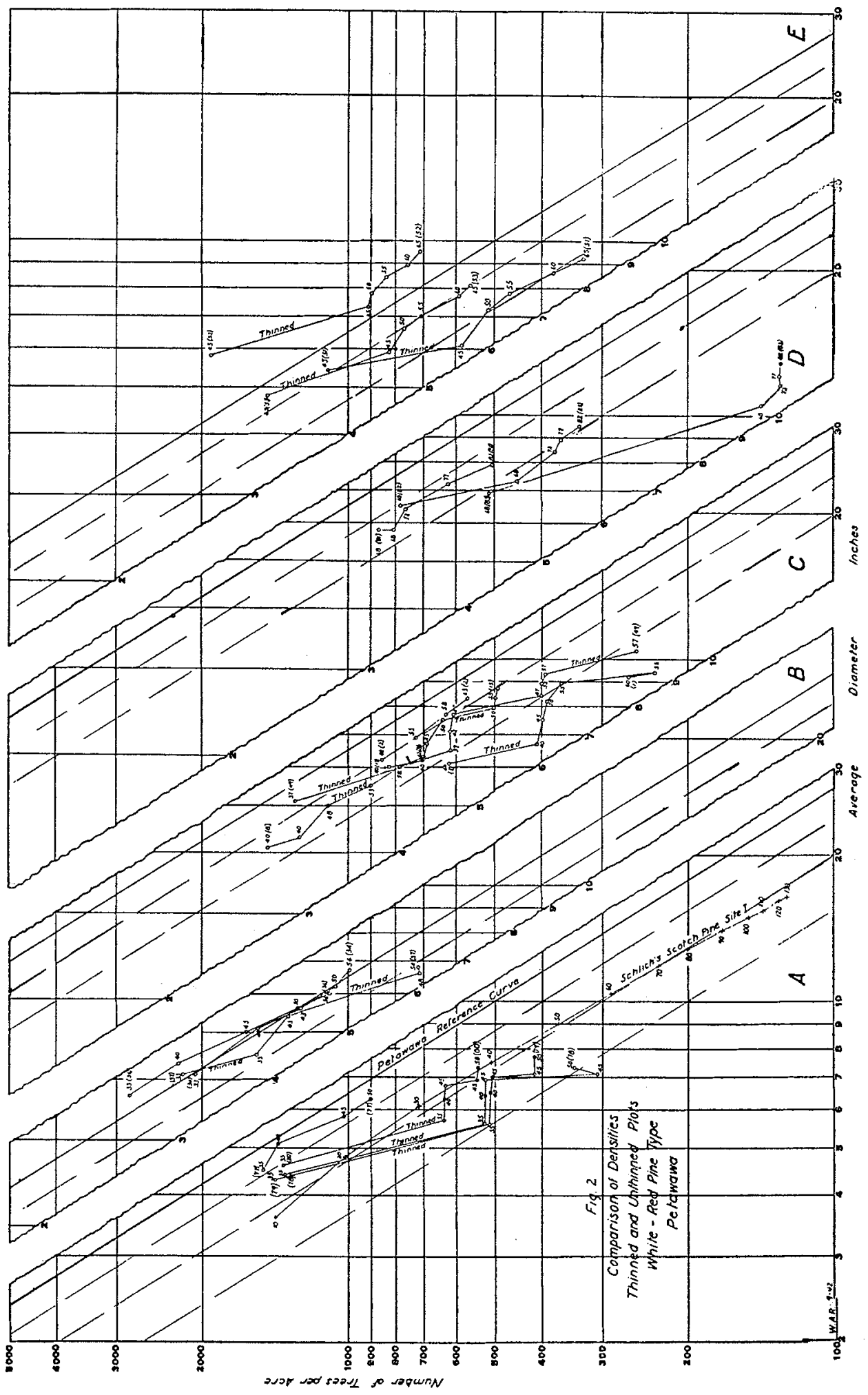


seed spots of pine. Plot 83 has, of course, been too heavily thinned and is now too far from the 500 S.D.I., although it has a very large average diameter (12.8 inches). It may be, of course, that, if the rotation for white pine on this plot is set at 100-120 years, the procedure used here of remov. ing a large amount at one thinning (70 years of age) will result in a better stand at maturity (one big thinning). It is doubtful, however, whether this plot will ever come back even to the 350 S.D.I., although it is swinging in that direction. At its present rate it will take another 30 years to reach the level of the 350 S.D.I. Plot 82 , with a fairly heavy thinning, has advanced well along the slope following the 300 S.D.I., having increased from 6.5 to 9.5 inches in average diameter, while still maintaining its number of trees around the 300 S.D.I. In comparison, Plot 81 , which was not thinned, has grown only from 5.8 to 7.9 inches and the number of trees after 14 years has now fallen to the 350 S.D.I.

In Section E, for comparison, a group of white pine-red pine plots in which there is a mixture of spruce, balsam fir and other species, is shown. It will be at once noticed that the form of the graph, "Number of Trees/ Average Diameter", is greatly different from the former figures. Moreover, this form is similar for all three plots concerned. All plots have been thinned. One of them is much above the 500 S.D.I. line and shows that these plots should not be considered or averaged with the other nearly pure red and white pine plots. However, it is apparent that the slope of the curves will follow that of the reference curve (500 S.D.I.).

The inclusion of data for thinned plots in this development of a density index for the white and red pine cover-type at Petawawa does not mean that this is a considered analysis of the results from thinning. It is included only to show that even after treatment the "Number of Trees/Average diameter" curve will follow the trend of the reference curve. It may be that, for each group of plots (same site), this density index graph may be useful in evaluating the results of thinning and determining the level at which the optimum growth per acre can be obtained. That is to say, it may assist in the development of a thinning technique for pure stands in each white and red pine site. The main finding is that Reineke's curve and formula can be used for pure stands of these species.

Figure 3 has been drawn for general use in determining density of white and red pine stands. The Petawawa reference curve through the point 500 trees per acre at 10 inches in diameter and represented by the equation log $\mathrm{N}=-1.605 \log \mathrm{D}+4.304$ is shown as a heavy line. Light lines below and above this reference curve represent $50,100,150,200,250,300,350$, $400,450,550$, and 600 trees per acre or S.D.I.

For convenience in determining the Stand Density Index of a stand of any species an alignment chart has been prepared by Mr. Reineke (Figure 4). As he points out in a covering letter, caution should be used in applying S.D.I. to stands with average diameter under 2.0 inches since frequency distributions of stems tallied are curtailed at the lower end. That is to say there may be many stems below the 1 inch class ( 4.5 feet). 


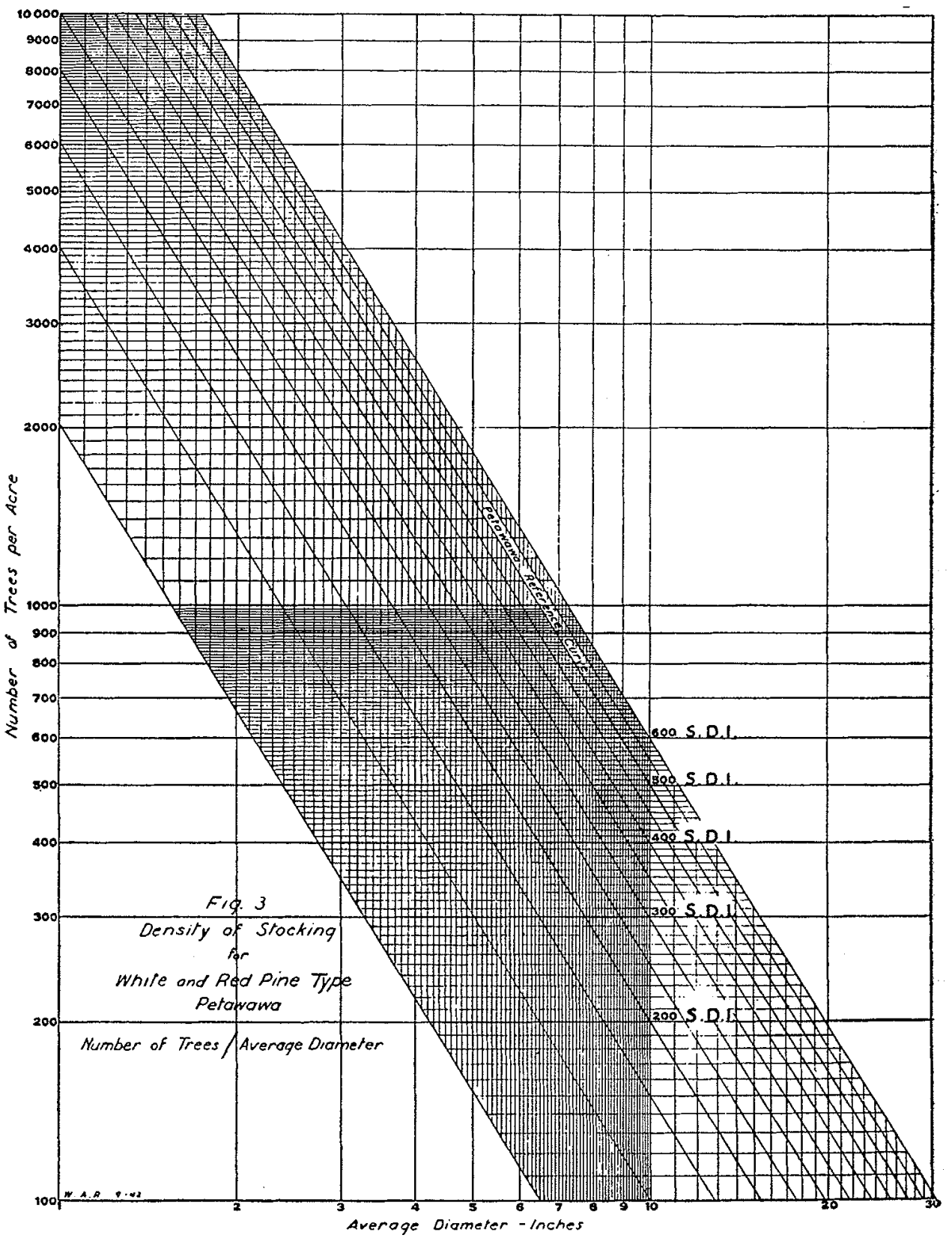



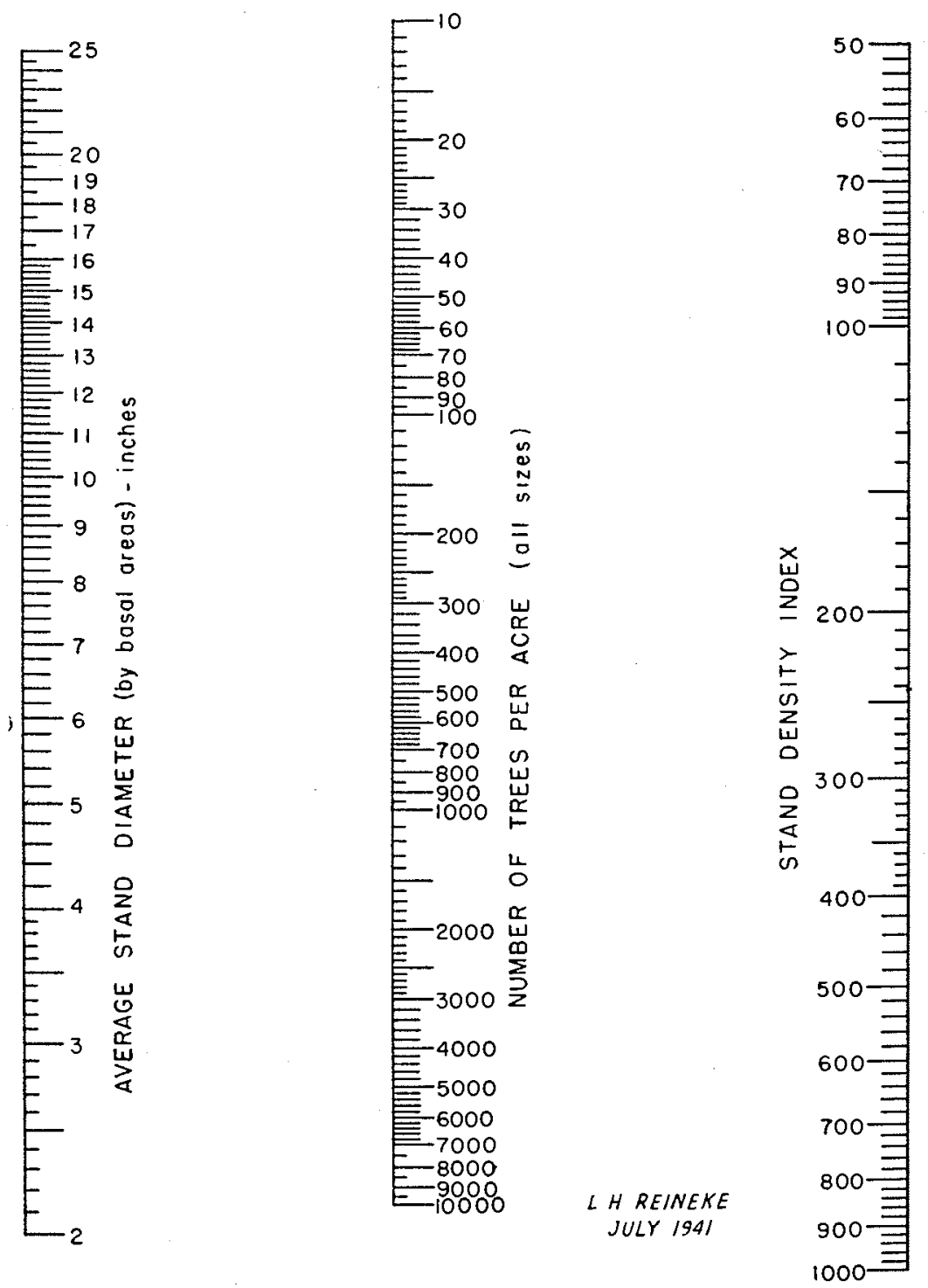

M $44390 \mathrm{~F}$

FIG. 4 


\section{Application in Thinnings And Improvement Cutting}

It is yet too soon in our program of thinning experiments to determine accurately the S.D.I. which will produce the best returns in volume and value. But this does not prevent the use of the present results in future work both on experimental plots and in marking for improvement and thinning. Exam. ination of Figures 1 and 2 shows that the line of optimum density probably occurs somewhere between 300 and 400 trees per acre at 10 inches average diameter. This is at least a guide and, translated into spacing, can be used in marking for thinning and improvement cutting.

If we assume that, in any thinning or improvement cutting on a large area at the station, at least 10 years will elapse before another intermediate cutting is made, it can be assumed that the lower S.D.I. (300) should be the guide. The following table has been read from Figure 3 and shows the number of trees per acre for each average diameter which should be present for 300 and for 400 S.D.I. These data have been translated into spacing in feet between trees. Thus, with an average diameter of 6.0 inches, the stand should be left after thinning with 680 trees per acre or 8 feet apart, while at 12.0 inches average diameter there should be left 225 trees per acre or about 14 feet apart. Actually, in practice, with the non-uniform condition of the woods to be considered, both the spacing columns should be used. Thus, in patches where the average diameter is about 6 inches, the spacing should be from 7 to 8 feet, and in other patches with 12 inches average diameter, the spacing should be from 12 to 14 feet.

Population and Spacing of Red and White Pine Stands after Treatment

\begin{tabular}{c|c|c|c|c}
\hline \hline $\begin{array}{c}\text { Average } \\
\text { Diameter } \\
\text { Inches }\end{array}$ & \multicolumn{2}{|c|}{ Number of Trees } & \multicolumn{2}{|c}{ Spacing-Feet } \\
\cline { 2 - 5 } & S.D.I. 300 & S.D.I. 400 & S.D.I. 300 & S.D.I. 400 \\
\hline 1.5 & 6300 & 8300 & 2.6 & 2.2 \\
2.0 & 3930 & 5220 & 3.3 & 2.9 \\
2.5 & 2750 & 3660 & 4.0 & 3.5 \\
3.0 & 2050 & 2730 & 4.6 & 4.0 \\
3.5 & 1600 & 2140 & 5.2 & 4.5 \\
4.0 & 1300 & 1720 & 5.8 & 5.0 \\
4.5 & 1070 & 1425 & 6.4 & 5.5 \\
5.0 & 900 & 1200 & 7.0 & 6.0 \\
5.5 & 780 & 1030 & 7.5 & 6.5 \\
6.0 & 680 & 900 & 8.0 & 7.0 \\
6.5 & $\mathbf{5 9 5}$ & 795 & 8.6 & 7.4 \\
7.0 & $\mathbf{5 2 8}$ & 705 & 9.1 & 7.9 \\
7.5 & 470 & 630 & 9.6 & 8.4 \\
8.0 & 425 & $\mathbf{5 7 0}$ & 10.1 & 8.8 \\
8.5 & 388 & $\mathbf{5 1 8}$ & 10.6 & 9.2 \\
9.0 & 353 & 473 & 11.1 & 9.6 \\
9.5 & 323 & 433 & 11.6 & 10.0 \\
10.0 & 300 & 400 & 12.0 & 10.4 \\
10.5 & 275 & 368 & 12.6 & 10.9 \\
11.0 & 256 & 342 & 13.0 & 11.3 \\
11.5 & 238 & 318 & 13.5 & 11.7 \\
12.0 & 225 & 296 & 13.9 & 12.1 \\
\hline
\end{tabular}


This table can be extended by use of Figure 3 and the spacing for larger average diameters determined. Thus, with an average diameter of 18 inches, the spacing should be from 17 to 19 feet. It will be noted as a practical memory guide how closely in the case of these larger average diameters the spacing in feet coincides with the diameter in inches.

In improvement cuttings where, say, an inferior or less desirable species is being removed from a mixed stand (poplar from a stand of red and white pine and poplar), stand density may be used for initial control of cutting but the final control will be the improvement achieved. Thus, where trees of the desired species are not numerous enough to provide optimum density, additional poplar should be removed at the first cutting unless such removal will have some adverse effect upon the growth of the pine or the site itself (limbiness of pine, exposure of soil to drying, weed growth or suckering of poplar, etc.) In this latter event, further improvement in stand composition must be left for subsequent improvement cuttings.

The Stand Density Index may well be used as a measure of the results from thinning and as an indicator of re-thinning after an interval long enough to permit the stand to make full response to the thinning and to return diameter distribution to a more nearly natural form. How long a period is necessary depends, of course, on the amount of disturbance and the rate of growth of the species. Five years in the case of white and red pine appear adequate for following the trend of development. This development should be plotted on the double-log graph as in Figures 1 to 3 .

A horizontal curve means that the number of trees is remaining the same and there is, as yet, no mortality. A horizontal curve and uniform or increasing five-year increments in average diameter indicates a condition of excessive, unproductive, free, growing space after thinning. (Plot 83 ages $72-82$, Fig. 2D). Horizontal curves but with diminishing average diameter increments (Plots 78, 79, ages 35 to 45 , Fig. 2A) indicate that all free growing space provided at the thinning has been productive, but is now being used up, yet the individual trees are still in good condition. If the curve drops off with diminishing diameter increments (Plot 1, 40.55 yrs., Fig. 2C), all free growing space was used and the stand contains individuals of low vigour which are about to be lost. When the curve parallels the S.D.I. curves after thinning, the thinning probably removed trees of low vigour which would have died naturally, or the removal of overtopping trees was completely compensated by the increment on the released trees.

\section{REFERENCES}

(1) Forest Terminology, Journal of Forestry, Vol. XV: 1. Jan. 1917.

(2) Reineke, L. H. Perfecting a stand-density index for even-aged forests. Journal of Agricultural Research, Vol. 46: 7. April 1, 1933.

(3) Gevorkiantz, S. R. and Zon, R. Second Growth White Pine in Wisconsin. Res. Bull. 98, Agric. Exp. Station, Un. of Wisc. 1930, page 31.

(4) Schlich's Manual of Forestry, Vol. III (3rd Edition), page 362. 